\title{
Redes de Empresas: Proposta de uma Tipologia para Classificação Aplicada na Indústria de Cerâmica de Revestimento(1)
}

\author{
ValmirEmil Hoffmann \\ F. Xavier Molina-Morales \\ M. Teresa Martínez-Fernández
}

\section{RESUMO}

Este artigo se insere no contexto da atualização da temática das redes de empresas presente na Academia nestes tempos. Seu objetivo é propor uma tipologia para a classificação das redes de empresas. Esta tipologia deriva da literatura consultada e dos casos estudados, vinculando-a a quatro indicadores: direcionalidade, localização, formalização e poder. Para a ilustração da aplicação desta tipologia foram consideradas três redes dentro da indústria de cerâmica de revestimento, duas no Brasil e uma na Espanha. A partir dos dados levantados com distintos instrumentos, como questionários, entrevistas não dirigidas e pesquisa bibliográfica, pôde-se aplicar a tipologia e inferir sobre a especificidade de cada rede e seu grau de aproximação com aquela considerada mais ajustada à tipologia proposta. Este exercício mostrou as diferenças entre essas redes, como, por exemplo, o fato de em uma mesma indústria, e até dentro de um mesmo país, as redes podem ser estruturas singulares e similares ao mesmo tempo. Mostrou também que, utilizando uma rede como referência, pode-se analisar a aproximação de outras redes de empresas a essa referência. A proposta ampliou a leitura de classificação que vinha sendo aplicada para além dos eixos de direcionalidade e formalização.

Palavras-chave: redes de empresas; tipologia de redes de empresas; indústria de cerâmica de revestimento.

\begin{abstract}
This article searches a contribution to actualize on firms networking theme existing on Academy nowadays. Its objective is to propose a classification typology to firm network. This typology comes from bibliographical research and from three clusters studied of ceramic tile industry, two on Brazil and one in Spain. The proposition links the clusters to four indicators: directionality; localization; formalization and power. Methodological proceedings were survey to CEOs; and supporting institutions; and bibliographical research. Results have shown each network specificity and its distance to more appropriate cluster according to typology. This work showed differences among networks such, in the same industry and country, two networks can be similar and singular at the same time. Also, using a network as reference, it was possible analyzing other networks to this one according to its characteristics. This proposition makes a contribution to network classification beyond directionality and formalization axis.
\end{abstract}

Key words: firm-networks; firm-networking typology; ceramic tile industry. 


\section{INTRODUÇÃO}

A julgar pelas palavras de Jarillo (1988, p. 31), que, na década de oitenta, considerava o tema das redes de empresas como assunto que estava em moda, poder-se-ia pensar que, passados mais de quinze anos daquela afirmação, a temática já seria menos interessante para a Academia. Contudo o que se vê é uma crescente retomada do assunto, talvez até permanente, visto que ele se incorporou como área em congressos nacionais e internacionais de expressão vinculados à estratégia.

O interesse despertado suscitou a busca de novas explicações e estudos para o gerenciamento de redes, sua utilidade e sua relação com o desempenho das empresas. Dentre os estudiosos que se ocupam do assunto destaca-se Oliveira Jr., Sommer, Colombini e Ikebe (2001) que avaliam a relação entre a competitividade das empresas e a estrutura de redes. Paiva Jr. e Barbosa (2001), por sua vez, indicam que as redes de empresas são cenários favoráveis para a exploração de oportunidades por parte das pequenas empresas, argumento corroborado posteriormente por Balestrin e Vargas (2003). Oliveira e Batista (2001), ao estudarem a indústria calçadista de Fortaleza, chegaram à conclusão de que as empresas trabalham com alianças, o que configura uma estrutura de redes, cujo escopo é a redução dos custos. Em trabalho que versou sobre a indústria têxtil de Santa Catarina, Ferreira e Wilhelm (2001) pesquisaram a percepção do empresariado em relação ao desenvolvimento de redes de base local como estratégia competitiva, e também ações que seriam necessárias para este fim. Pereira e Pedrozo (2003), ainda versando sobre o mesmo assunto, procuraram desenvolver um modelo analítico do desenvolvimento de redes interorganizacionais. No que se refere à temática, não se pode deixar de citar Bauer (2003) quando, de sua parte, tratou de salientar que as redes permitem que as práticas locais sejam incorporadas, aumentando o comprometimento dos participantes, com o objetivo de toda a rede.

Este artigo se insere nesse contexto de atualização temática. Seu objetivo é propor uma tipologia para a classificação das redes de empresas. Ele começa com uma discussão sobre o marco teórico existente sobre as redes de empresas, com seus conceitos e suas características. Posteriormente, faz a proposição de uma tipologia para a classificação das redes. Na sequiência, apresenta uma ilustração com a aplicação desta tipologia para a classificação de três redes de uma mesma indústria, que se encontram aglomeradas territorialmente. 


\section{Marco Té́rico}

Jarillo (1988) fez referência à existência dos primeiros trabalhos sobre redes, ainda na década de sessenta, ligados às organizações sem fins lucrativos. A Academia, naquele período, não associava a temática da estratégia e da competição entre empresas com a constituição de redes. A predominância do modelo de explicação da competição, através da microeconomia, a partir de Porter (1980), pode ter contribuído para essa dissociação, e é o que afirma Jarillo (1988).

Porter (1980) entendia que a competição era um jogo de forças entre as partes, e que o êxito de uma empresa se baseava na escolha da melhor estratégia genérica (diferenciação, custo ou enfoque), e no poder de mercado que a empresa tinha. Esse poder poderia ser avaliado em função dos consumidores, dos fornecedores, da própria competição na indústria, da capacidade de substituição dos produtos e na possível entrada de novos atores. A partir dessa visão, era complexo imaginar que a vantagem competitiva da empresa poderia não estar, necessariamente, em sua força de mercado. Deve-se levar em consideração, no entanto, o fato de o texto de Porter (1980) ter sido elaborado na segunda metade dos anos setenta, quando o mundo atravessava forte retração da atividade econômica e, assim, parecia lógico explicar a sobrevivência das empresas através de relações puramente competitivas.

Os trabalhos de Miles e Snow (1986), Thorelli (1986), Jarillo (1988) e posteriormente Powell (1990) levaram à construção de terminologia própria. Nas palavras de Miles e Snow (1986), uma rede de empresas é a combinação única de estratégia, estrutura e processo de gestão a que se refere. Já no conceito de Thorelli (1986), uma rede de empresas é o que há de intermediário entre uma simples empresa e o mercado, isto é, duas ou mais empresas que, através da intensidade de sua interação, constituem um subconjunto de um ou vários mercados. Generalizando, uma rede pode ser vista como posições ocupadas por empresas, famílias, ou unidades estratégicas de negócio, inseridas em contextos diversificados, associações comerciais e outros tipos de organizações. Jarillo (1988) descreve as redes como acordos de longo prazo, com propósitos claros, entre empresas distintas, mas relacionadas, que permitem àquelas empresas estabelecerem ou sustentarem uma vantagem competitiva em face das empresas presentes fora da rede. Powell (1990) escreve que as redes são o caminho intermediário entre as estruturas competitivas de mercado, a posição individual ocupada pela empresa e as hierarquias presentes nas relações entre as partes. Neste trabalho, emprega-se a definição de Jarillo (1988), na medida em que este considera as redes como acordos de longo prazo entre empresas e instituições de suporte industrial. 
Dessa forma, se as redes são estruturas, são acordos, com escopo relacionado à vantagem competitiva, as circunstâncias que podem ensejar sua formação estariam ligadas à necessidade dessa vantagem competitiva que, no contexto atual, se dá praticamente em todos os mercados. Dentro dessa lógica, ao que tudo indica, as empresas deveriam formar redes para permanecer no mercado. Mas, a partir daí, surge uma questão: por que algumas empresas formam redes e outras não?

As motivações para a formação de rede podem ser diversas: complexidade de produtos; troca de conhecimento, aprendizagem organizacional e disseminação da informação; demanda por rapidez de resposta; confiança e cooperação; e defesa contra a incerteza. Elas podem ser formatadas em função da complexidade de produtos e serviços e seu desenho, sua produção e sua distribuição. É raro o produto que não contenha componentes oriundos de distintas tecnologias, e o serviço que não reúna distintas capacidades especializadas. Igualmente é rara a empresa que não estabeleça suas atividades de aquisição de matéria-prima, marketing ou distribuição a partir de pessoas com capacidades específicas do mercado determinado (Håkansson \& Snehota, 1989).

A troca de distintas competências - conhecimentos e capacidades - é mais provável de ocorrer nas redes, e esta é também uma justificativa para sua criação. Por se constituírem em formato de organização, cuja ênfase na forma lateral de comunicação e obrigação mútua é bem compreendida pela mão-de-obra, faz-se necessário que os indivíduos tenham um conjunto de capacidades aplicáveis a um grande leque de atividades (Dyer, 1996).

As redes também criam incentivos para aprendizagem e disseminação da informação, permitindo que idéias se transformem em ações rapidamente. Em trabalho realizado por Uzzi (1996), foi mostrado que os agentes estão mais dispostos a trocar informações de caráter estratégico com aquelas empresas que estão mais próximas e que fazem parte de sua rede.

Um dos desafios encontrados pelas empresas, hoje, concerne à busca pelo equilíbrio de forças com as variações que o mercado apresenta. Dentro deste aspecto, a questão da rapidez de resposta torna-se item fundamental; uma das vantagens das redes é a velocidade com que as informações são transmitidas. As redes são baseadas em complexos canais de comunicação, que permitem que as demandas existentes no mercado sejam alcançadas com maior rapidez (Powell, 1990).

As redes de empresas apresentam certas características que lhes são particulares, em relação às empresas: relatividade nos papéis dos atores organizacionais; interação; interdependência; especialização; complementaridade; 
e competitividade entre redes. Apesar da proposta deste artigo centrar-se em tipologia relacionada indiretamente com essas características, a título de ampliação da discussão teórica, apresentam-se essas características com maior detalhamento, na seqüência.

A relatividade nos papéis dos atores organizacionais explica-se pelo fato de as redes de empresas constituírem um entorno limitado pelo conjunto das relações que estabelecem entre si e entre seu ambiente. Neste entorno limitado, podese pensar que o papel de cada parte não é definido tão claramente, como determina, por exemplo, o modelo de Porter (1980), Esser, Hillebrand, Messner e Meyer-Stamer (1994). A visão de redes de empresas enfatiza que os atores econômicos jogam diferentes papéis não só em relação a diferentes contrapartes (uma empresa é fornecedora de um cliente e consumidora de um fornecedor), mas também é uma contraparte isolada. Ramírez (1999) escreve que em uma rede de empresas, um ator econômico A pode ser simultaneamente fornecedor de uma empresa B; pode ser seu parceiro; pode ser seu competidor e pode ser, ainda, seu consumidor.

Quanto à interação, não se encontraram estudos que explicitem que em uma rede pode haver passividade entre as partes e que essa passividade seja benéfica para elas. A interação das partes é muito maior que uma adaptação passiva. Quando interagem, seus problemas são confrontados com soluções, suas habilidades com necessidades etc. Conhecimento recíproco e capacidades são revelados e desenvolvidos juntamente e em uma dependência mútua pelas partes. Veja-se, por exemplo, o caso abordado por Martinez-Fernández (2001), em seu estudo sobre as redes existentes na indústria espanhola de cerâmica de revestimento.

Com relação à interdependência das partes, Håkansson e Snehota (1989) esclarecem que, como instrumento dessas relações interorganizacionais, um conjunto complexo de interdependências se desenvolve gradualmente. Dadas as naturezas distintas das partes, as interdependências no relacionamento se tornam mais fortes. Através desse relacionamento, cada parte ganha acesso aos recursos dos demais. Os atores poderão, em certo grau, mobilizar e usar recursos controlados por outros atores nas redes. Os limites das empresas são mais permeáveis, superáveis e mutáveis. Thorelli (1986) escreve que, provavelmente, a parte mais saliente do ambiente da empresa sejam as outras empresas. À luz do Paradigma de Redes, talvez o que se pode sugerir é que a porção mais saliente de uma empresa que faz parte de uma rede são as outras empresas pertencentes à rede.

A especialização das atividades das empresas se dá em função das vantagens da escala. As empresas geralmente se situam no âmbito do componente e não do 
sistema como um todo. Focando assim, elas farão melhor e poderão estabelecer alianças para administrar a interdependência do âmbito do sistema. Desta forma, as redes oferecem vantagens óbvias para seus membros (Gomes-Cásseres, 1994). Então, as redes podem ser consideradas

como alternativas à integração vertical e a diversificação e como um instrumento de se conseguir novos clientes e/ou países adicionais [...]. Fazer parte de uma rede pode reduzir os riscos relativos tanto da participação individual em um mercado como também à integração total (Thorelli, 1986, p. 46).

Os atores podem utilizar a existência de complementaridade ou competitividade em suas relações em diferentes caminhos, assim como eles interagem uns com os outros. Em função da interdependência da empresa com as outras entidades, fica difícil desconectar a empresa de sua rede, já que desta forma ela perde sua identidade (Håkansson \& Snehota, 1989). A efetividade de uma empresa não está tanto em sua capacidade de adaptação ao ambiente, quanto em sua relatividade ao contexto. Essa relatividade inclui as atividades de quaseintegração, relativas ao compartilhamento de tecnologia para o desenvolvimento de produtos, p.ex.; a conexão com seus recursos e os da própria rede e a influência de sua percepção e das demais partes nas dimensões importantes do contexto.

A competitividade entre redes ocorre principalmente pela eficiência da especialização, ainda que, como escreve Hansen (1992), a empresa só não vai verticalizar-se, caso seja mais eficiente fazer fora que dentro. A questão que transcende a busca do modelo ideal do dilema comprar/fazer está relacionada à maneira como determinados arranjos organizacionais podem tornar-se mais eficientes. O que se pode pensar é que, de fato, como afirma Drucker (1994), não são os maiores que superam os menores, e sim os mais rápidos que ultrapassam os mais lentos. Não se trata mais de tamanho e sim de capacidade de competição e de velocidade de resposta ao mercado. Pode-se entender que, para as pequenas empresas, a instituição de redes seria mecanismo viável pelo qual atingiriam determinado volume de escala que lhes permitiria competir com empresas de maior porte. Isso leva a pensar que redes maiores seriam mais eficientes que menores. Contudo, como assinala Gomes-Cásseres (1994), para atrair novos membros à rede tem de ser capaz de mostrar potencial para juntar benefícios. A constituição de redes maiores leva, conseqüentemente, a maiores custos de sua manutenção, já que é necessário mais tempo de dedicação de reunião e trocas de informações. Os benefícios, no entanto, podem se ver diluídos ante essa realidade. 


\section{TIPOLOGIA}

Pensar em tipologia em termos de redes é um risco, pois existem várias classificações e conceitos que se equivalem, como cadeia dinâmica (Miles \& Snow, 1986); rede focal (Thorelli, 1986); redes estratégicas (Jarillo, 1988); redes (Lorenzoni \& Baden-Fuller, 1995; Powell, 1990; Uzzi, 1996); sistema de produção (Storper \& Harrison, 1991); distritos industriais ${ }^{(2)}$ (Hansen, 1992). aliança de grupos (Gomes-Cásseres, 1994); e co-produção de valor (Ramírez, 1999). Com vistas a unificar os conceitos e a terminologia empregada, optou-se por utilizar uma expressão mais objetiva: redes de empresa.

O desenvolvimento dessa tipologia decorre de uma pesquisa bibliográfica realizada com autores que vêm trabalhando esse tema no exterior e no Brasil. No exterior, alguns desses autores, como Miles e Snow (1986); Thorelli (1986); Jarillo (1988); Powell (1990), encontram-se entre as primeiras referências a discutir a temática das redes no contexto acadêmico, a partir de um ponto de vista socioeconômico. Posteriormente, pode-se incluir as contribuições de Grandori e Soda (1995) e Castells (1999). No Brasil, as contribuições começaram a surgir principalmente a partir do ano 2000; por exemplo, com as obras de Amato Neto (2000); Casarotto Fo. e Pires (2001); Teixeira e Guerra (2002,); Pitassi e MacedoSoares (2003); Carrão (2004); e mais recentemente por um livro organizado por Amato Neto (2005).

As classificações que têm sido freqüentemente apresentadas na literatura pautam-se em dois eixos: direcionalidade e formalização. Este é o caso, por exemplo, do trabalho de Castells (1999) e Carrão (2004). Com referência à formalização, Siqueira (2000), ao discutir as redes no contexto dos serviços públicos, assume que elas se caracterizam por serem acordos de base contratual. Teixeira e Guerra (2002, p. 95), ao falar das redes de aprendizagem, ressaltam que "as redes podem ser de dois tipos: verticais e horizontais". À direcionalidade vertical os autores incorporam elementos que podem ser classificados como poder, indicando que nas redes verticais a empresa coordenadora assegura o controle da cadeia de produção. Tratando de redes estratégicas, Pitassi e Macedo-Soares (2003), em outras palavras, relacionam as possibilidades de formalização, direcionalidade e poder, dentro de redes virtuais. Os autores acrescentam a idéia de característica das relações, utilizando aspectos relacionados à densidade. Sobre formalização, em obra anterior, Grandori e Soda (1995) apresentam tipologia de redes de empresas de base contratual e não contratual; também ressaltam a existência de poder entre as unidades, usando a idéia de simetria. 
Além disso, a essa pesquisa bibliográfica, aliaram-se os resultados de dois trabalhos empíricos realizados por estes autores, cuja fonte é omitida para avaliação deste texto. Aqui, exploram-se quatro dessas características, resumidas no Quadro 1 e discutidas na seqüência.

\section{Quadro 1: Resumo da Tipologia Proposta}

\begin{tabular}{|l|l|}
\hline Indicadores & Tipologia \\
\hline a) Direcionalidade & Vertical \\
& Horizontal \\
\hline b) Localização & $\begin{array}{l}\text { Dispersa } \\
\text { Aglomerada }\end{array}$ \\
\hline c) Formalização & $\begin{array}{l}\text { Base contratual formal } \\
\text { Base não contratual }\end{array}$ \\
\hline d) Poder & $\begin{array}{l}\text { Orbital } \\
\text { Não orbital }\end{array}$ \\
\hline
\end{tabular}

Fonte: elaboração própria.

a) O primeiro dos indicadores das redes de empresas é a direcionalidade. Essa característica descreve a direção das relações entre as partes e enfatiza que há dois tipos predominantes: as redes verticais e as redes horizontais. As redes verticais são aquelas em que cada processo é realizado por empresas especializadas, e não concorrentes, e que não atuam no mesmo mercado. Essas empresas adotam a estratégia de especialização, determinando sua competência essencial, em alusão clara aos escritos de Prahalad e Hamel (1994), terceirizando aqueles processos que não agregam valor para seu produto/serviço. Isso permite às empresas a aquisição dos benefícios da especialização, que são o foco no negócio, ao mesmo tempo que adquirem flexibilidade por não estarem presas a atividades não essenciais (Jarillo, 1988).

Esse é o caso da indústria de automóveis, como referenciou Dyer (1996). Em seu estudo, o autor mostrou que as empresas formam redes com fornecedores capazes de gerar suprimentos de forma rápida, com altos graus de avanço tecnológico. Embora seu estudo tenha contemplado empresas japonesas e americanas, mesmo no Brasil, como é de conhecimento comum, pode-se verificar esse tipo de estrutura industrial. O propósito desse tipo de rede é o de se alcançar a eficiência coletiva nos processos. No caso estudado por Henry, Oinch e Russel (1996), ficou demonstrado que em redes especializadas os ganhos podem advir igualmente da rapidez de resposta das partes. Para chegar a tal conclusão, os autores estudaram uma rede verticalizada da indústria de carros de competição esportiva, onde os avanços tecnológicos não podem ser ocultados por um período de tempo muito longo. Assim, a velocidade de imitação e assimilação da 
tecnologia gerada pelos concorrentes é um ponto de relevância para a manutenção das empresas.

As redes horizontais são aquelas estabelecidas entre empresas que competem em termos de produtos e/ou mercados. Nesse caso, o objetivo da rede deve sempre estar dirigido aos ganhos que se podem obter pela união entre as partes. No trabalho de Kristensen (1993), sobre redes na Dinamarca, ficou evidenciado que as empresas empregam relações horizontais até mesmo em função dos objetivos em termos de desenvolvimento de projeto de produto e processos. Essa idéia foi corroborada posteriormente por Casarotto Filho e Pires (2001), que acrescentaram ainda que as redes horizontais podem ser constituídas para se implementar a exportação.

Ressalta-se, ainda, que uma empresa pode estar presente tanto em redes verticais como horizontais. Um caso estudado desse tipo de rede é apresentado por Vet e Scott (1992). Os autores mostraram que na região sul da Califórnia, nos Estados Unidos, a indústria de equipamentos odontológicos cresceu em vinte anos cerca de $110 \%$ e está caracterizada tanto por possuir vínculos verticais com fornecedores e clientes, como por possuir vínculos horizontais entre as empresas.

b) Em termos de localização, as redes podem ser dispersas ou aglomeradas. Redes dispersas são aquelas que se relacionam e intercambiam bens e serviços através de processo avançado de logística, que permite superar as distâncias. Tipicamente são redes verticais, com escopo na produção de bens e serviços. Esse tipo de rede é mais ressaltado nos trabalhos de Thorelli (1986) e Powell (1990). Esses dois autores evidenciam aspectos de relações que parecem indicar dispersão, embora não tratem o tema de maneira especifica. No trabalho de Dyer (1996), a indústria automobilística estudada em dois países distintos pode ser classificada como rede dispersa geograficamente. Também as franquias podem ser classificadas dessa maneira, visto que a dispersão passa a ser um escopo da rede, visto que, como estudadas por Cavalcante e Arruda (2003), elas se estabelecem com o propósito de ampliar a presença de mercado. As redes aglomeradas territorialmente se caracterizam pelo fato de manterem relações que, muitas vezes, se estendem além daquelas puramente comerciais. Como em comunidade de pessoas (Molina-Morales, 2001a), nas redes cria-se uma atmosfera de confiança, que facilita as relações não contratuais (Uzzi, 1996). Além das empresas, nesse tipo de rede é possível encontrar também instituições de suporte empresarial, como universidades, centros de tecnologia, e instituições governamentais. Schmitz (1993) relata que em Baden-Würtemberg, Alemanha, as relações de rede se dão de forma vertical entre empresas de diferentes tamanhos, e de forma horizontal entre empresas menores e instituições. Molina-Morales, Lopez-Navarro e Guia-Julve (2001) destacam o 
papel das instituições universitárias como preparadoras de mão-de-obra especializada em distintos níveis, e também como centros de pesquisas, voltados à atividade principal da região.

c) Segundo Gomes-Cásseres (1994), as redes podem estar constituídas por vários tipos de alianças, que vão desde as mais formais, como joint venture, até as mais simples, como a colaboração informal. Em termos de formalização, as redes podem ser estruturas formalizadas, de base contratual, ou ser informais, de base não contratual. Esses distintos tipos de configuração são formatados pelo escopo que a rede pode ter. Isso significa que não há um tipo ideal de rede, mas diferentes tipos de situações podem levar a diferentes acordos e interações das empresas. Como exemplo, pode-se citar que, em contexto de aglomeração territorial, as pesquisas desses autores têm encontrado mais comumente a constituição de redes horizontais e de base não contratual. Ainda, quando a motivação para a formação da rede seja a ampliação da cobertura de mercado, comumente podem-se encontrar redes verticalizadas, de base contratual, como as franquias.

As redes de base contratual são estabelecidas com o fim de se prevenir o que Williamson $(1975,1991)$ chama de comportamentos oportunistas. Como esses comportamentos oportunistas podem lesar uma das partes, geram-se custos nas transações, através do estabelecimento de contratos; ao mesmo tempo esses contratos vão servir para que a empresa possa ter mais garantias acerca do comportamento de sua contraparte. Exemplos desse tipo de rede foram descritos por Wittmann, Negrini e Venturini (2003). No caso estudado, tem-se o exemplo do Governo do Rio Grande do Sul, que vem implementando redes de empresas, com base contratual, estabelecendo regras de conduta, direitos e deveres para as empresas interessadas. No estudo de Wittmann et al. (2003), os benefícios se relacionam à intenção dos integrantes em participar de outras redes, bem como aqueles oriundos de maior poder de negociação.

As redes de base não contratual são aquelas estabelecidas em função da confiança gerada. Granovetter (1985) resume dizendo que as relações econômicas estão misturadas com as sociais. E essas relações não se dão apenas no âmbito gerencial, mas também no âmbito onde as transações se realizam. Um exemplo disso são as relações entre comprador e vendedor. Essas relações podem ser longas (entre 5 e 25 anos). Assim sendo, existe um custo de substituição que as empresas não estão dispostas a ter. Com o passar do tempo, a empresa cria relações e acumula conhecimento com respeito a elas, que se tornam um ativo, permitindo-lhe agir sem temer comportamentos oportunistas, a posteriori, pelo custo que a outra empresa teria, se perdesse a confiança nela depositada. No caso das redes de base não contratual, o dispositivo encontrado para que não 
haja fraude nas relações está dirigido pelas sanções que podem surgir, que vão desde rumores até o ostracismo: exclusão por períodos curtos ou até definitiva (Jones, Hersterley, \& Borgatti, 1997).

d) No indicador que avalia poder, o que parece estar claro é que nas redes, pelo menos naquelas formadas entre empresa e fornecedores, existe hierarquia. Ao se analisar o estudo de Dyer (1996), fica elucidado que todas as montadoras de automóveis possuem maior poder de decisão em relação aos destinos que a sua rede vai tomar do que as demais empresas-membro. No caso da Toyota, que é a rede mais desintegrada, com intensidade maior de especialização por parte dos fornecedores, o poder pode estar sendo exercido pelas visitas constantes de engenheiros e pelas horas aplicadas a acompanhar o fornecedor no desenvolvimento de novos produtos, bem como na troca de informações confidenciais. No caso da grande empresa que é mais integrada, as relações são tipicamente de queda de braço (arm-length ties) e o poder é estabelecido na base da barganha. Essa é a rede que se pode classificar como orbital, na medida em que possui um centro de poder, ao redor do qual as demais empresas circulam. Nos dois casos, a rede foi montada a partir de uma empresa central, ou como chamam Lorenzoni e Baden-Fuller (1995), um centro estratégico. Na visão de Jarillo (1988), essa configuração orbital é vantajosa para a empresa, pois a empresa central de uma rede, quando comparada a uma empresa verticalizada, será mais eficiente, pois captura economias de escala de suas associadas, que seus competidores não podem obter, visto que seus custos de transação os forçam à integração.

A rede não orbital é aquela onde cada parte tem a mesma capacidade de tomada de decisão. O estudo que se está realizando sobre a indústria do vestuário em Santa Catarina vem mostrando claramente que as empresas trabalham de maneira cooperada, sem a existência de um centro de poder (Hoffmann, 2004). Nesse caso, as instituições são formadas pelas empresas, e as diretorias são estabelecidas a partir do voto direto das empresas. Qualquer empresário associado pode propor uma chapa e concorrer ao pleito.

\section{UMA ILUSTRAÇÃo EMPÍRICA}

Para poder testar a proposição dessa tipologia, decidiu-se verificar sua aplicação em três redes de empresas. Assim, foi desenvolvida uma pesquisa na indústria brasileira e espanhola de cerâmica de revestimento, que procurou avaliar seus fatores competitivos (Hoffmann, 2002), e parte dos resultados daquele trabalho serve para ilustrar este artigo. 


\section{Metodologia Empregada}

As informações sobre as redes no Brasil e na Espanha foram obtidas de três maneiras. Foi aplicado um questionário a dirigentes de 39\% das plantas industriais brasileiras e 65\% de empresas espanholas. No Brasil, foram pesquisadas as concentrações de Criciúma (SC) e Santa Gertrudes (SP), visto que, além da aglomeração, também possuem infra-estrutura de suporte empresarial, conforme Coelho, Suslick e Souza (2000); Caridade e Torkomian (2001); Goularti Filho (2001); Meyer-Stamer, Maggi e Siebel (2001). Foram contatadas oitenta e uma empresas, de um total de cento e trinta e uma existentes no período. Quarenta e nove aceitaram participar do trabalho, o que configurou uma amostragem por conveniência. Na Espanha, assumiu-se a representatividade da amostra indicada pelos criadores da base de dados (Molina-Morales, 2001b).

Para a avaliação dos indicadores presentes na tipologia proposta, foram utilizadas as questões presentes no Quadro 2, a partir de uma escala contínua de 1 (para a intensidade mais baixa) e 5 (para a intensidade mais alta). Essas questões derivam da pesquisa realizada para avaliar os fatores competitivos da indústria cerâmica de revestimento, e tiveram como fundamentação teórica os textos de Hall (1992, 1993); Foss e Koch (1996); Jones, Hersterley e Borgatti (1997); Enright (1998); Pinch e Henry (1999), entre outros, e que haviam sido aplicados anteriormente por Martínez-Fernández (2001).

O tratamento dos dados utilizou a estatística descritiva. As médias foram comparadas com Castellón que, para efeito desta análise, foi considerada a rede que atingiu a parte superior da escala (5) em todos os indicadores. A ponderação se deu em função da distância entre o resultado obtido em Casetllón (5) e aquele obtido nas outras redes. Essa simplificação foi utilizada neste trabalho em função da ilustração da tipologia que se pretendia fazer. O tratamento mais completo dessas informações encontra-se naquele trabalho que focou os fatores competitivos e que está sendo omitido nesta avaliação.

Também foram realizadas entrevistas não dirigidas, como recomendam Richardson (1999), com dirigentes e executivos institucionais do setor. Essas informações auxiliaram na interpretação dos dados e para a compreensão da realidade de cada rede, principalmente nos indicadores formalização e poder. $\mathrm{O}$ teor das entrevistas versou igualmente a informação sintetizada no Quadro 2. Por fim, utilizou-se a pesquisa bibliográfica. Os resultados desse trabalho culminaram no estabelecimento de uma discussão individual de cada rede. 


\section{Quadro 2: Indicadores e Informação Utilizada}

\begin{tabular}{|c|c|}
\hline Indicadores & Informação utilizada \\
\hline 1) Direcionalidade & $\begin{array}{ll}\text { - } & \text { Quantidade de processos executados internamente } \\
\text { - } & \text { Localização dos fornecedores } \\
\text { - } & \text { Disposição para terceirização } \\
\text { - } & \text { Atuação semelhante aos competidores, com relação aos fornecedores }\end{array}$ \\
\hline 2) Localização & $\begin{array}{ll}\text { - } & \text { Distância média entre as plantas industriais } \\
\text { - } & \text { Capacidade técnica local } \\
\text { - } & \text { Participação dos eventos de classe (empresarial) } \\
\text { - } & \text { Mobilidade interna da mão de obra }\end{array}$ \\
\hline 3) Formalização & $\begin{array}{ll}\text { - } & \text { Possibilidade de transferência informal de informações } \\
\text { - } & \text { Disposição para a subcontratação } \\
\text { - } & \text { Aceitação de acordos de cooperação com empresas, que não de produção } \\
\text { - } & \text { Intensidade das relações sociais na rede. } \\
\text { - } & \text { Transferência de informação sobre produtos e tecnologia } \\
\text { - } & \text { Transferência de informação sobre mercados e consumidores } \\
\end{array}$ \\
\hline 4) Poder & $\begin{array}{ll}\text { - } & \text { Importância das instituições de suporte empresarial } \\
\text { - } & \text { Reputação externa dos produtos locais } \\
\text { - } & \text { Reputação externa das empresas locais } \\
\text { - } & \text { Número de funcionários diretos das empresas presentes na rede } \\
\text { - } & \text { Decisões similares a dos competidores sobre comprar ou fazer }\end{array}$ \\
\hline
\end{tabular}

Fonte: Hall (1992, 1993); Foss e Koch (1996); Jones, Hersterley e Borgatti (1997); Enright (1998); Pinch e Henry (1999); Martínez-Fernández (2001).

\section{Caracterização das Redes Estudadas}

A indústria cerâmica de revestimento está presente no Brasil desde os anos vinte do século passado e, atualmente, possui quatro concentrações (Goularti Filho, 2001), mas em apenas duas há instituições de suporte industrial e que foram objeto deste estudo: uma na região de Criciúma (SC) - 9\% das plantas industriais brasileiras - e outro na região de Santa Gertrudes (SP) - 31\% das plantas industriais brasileiras - sendo responsáveis, juntas, por $65 \%$ da produção nacional de cerâmica. O restante da produção e das plantas industriais está espalhado por todo o país, com menor presença na região norte.

Como se pôde constatar com o trabalho de campo, com as informações fornecidas pelo sindicato da categoria (Sindicato, 1998) e também por MeyerStamer (1999), a concentração industrial de revestimento cerâmico em Criciúma é composta por duas grandes empresas e cerca de outras treze empresas médias. A distância média entre elas é de $55 \mathrm{~km}$. A maioria das empresas tem entre 101 e 500 funcionários. Essa dimensão chama a atenção, já que está relacionada com o grau de verticalização dos empreendimentos. A maioria das empresas possui todos os processos integralizados, desde a lavra da argila ${ }^{(3)}$ até a cocção.

Nessa região, o grau de formalização nas relações é alto. Todos os acordos são de base formal, mesmo porque o próprio tamanho das empresas inibe a informalidade. Dessa maneira, essa formalização está relacionada com o fato de 
que nessa rede se evidencia uma bipolarização, criando-se o que alguns entrevistados chamaram de dois times rivais. Apesar de ter existido maior cooperação entre as empresas na década de noventa do século XX (MeyerStamer, 1998, 1999), as duas de grande porte, presentes na região, acabam por desenvolver acordos, essencialmente com fornecedores e menos intensamente com competidores (Meyer-Stamer, Maggi, \& Siebel, 2001), quase sempre de maneira formal, motivadas pelo receio de comportamentos oportunistas por parte de sua rival, como elucidaram alguns entrevistados.

A aglomeração industrial cerâmica de Santa Gertrudes se localiza em nove cidades dentro de um raio de $50 \mathrm{~km}$ em torno da cidade central, com a maioria das empresas empregando entre 51 e 200 funcionários e concentrando, já no ano 2000, 40\% (181 milhões de metros quadrados) da produção de pisos e revestimentos brasileiros (Caridade \& Torkomian, 2001).

Ainda que com empresas de menor porte, pequenas e médias em sua maioria, o grau de verticalização é alto; a lavra é feita integralmente por cada cerâmica, que também é proprietária de suas jazidas, na maioria dos casos. Em alguns casos, o transporte do produto é feito com frota própria.

A estrutura das empresas é mais informal, o que se reflete também em suas relações. Essa informalidade atinge distintos âmbitos, e é possível notá-la igualmente nas relações entre fornecedores e entre as empresas. Araújo, Romachelli e Martins (2001) destacam várias iniciativas relacionadas à cooperação horizontal entre as empresas, como a certificação da qualificação dos produtos e a criação de um centro de tecnologia cerâmica.

Nesse contexto, e também em função do tamanho das empresas e de seu relativo poder de mercado, a estrutura de poder na rede é bastante diluída, com alternância na direção das associações, o que permite que não haja nenhum grupo hegemônico.

Já na Espanha, a indústria existe desde o século IX, mas foi nos anos sessenta e setenta do século XX que recebeu maior impulso governamental. A concentração é mais intensa que no caso brasileiro, com cerca de 144 empresas em um raio de 25 km na Província de Castellón (Martínez-Fernández, 2001): 75\% delas com até 100 funcionários (Asociación Española de Fabricantes de Azulejos, Pavimentos y Baldosas Cerámicas [ASCER], 2002). Ela concentrava, já no ano 2000, 93\% da produção nacional e em 2001 o ramo ceramista atingiu o maior nível de produção mundial, superando a Itália (ASCER, 2002).

A existência de grande número de fornecedores evidencia grau relativamente alto de especialização e a intensa cooperação entre empresas e seus fornecedores. 
Os trabalhos de Molina-Morales (1997) e, posteriormente, de Martínez-Fernández (2001) comprovaram a existência de alto grau de cooperação horizontal. A formalização, nesse caso, é menor, dado que as empresas até mesmo subcontratam os serviços de seus competidores ante a necessidade de atender a um pedido de maior monta (Molina-Morales, 1997).

\section{Aplicação da Tipologia}

Para se efetuar a análise é necessário pensar não em termos de país e sim em termos de redes como estruturas autônomas. Em outras palavras, o âmbito de análise não é o país, mas as redes de empresas de uma mesma indústria localizadas no país. Levando-se em conta as características de complementaridade e a especialização das atividades mencionadas anteriormente, pode-se entender que a autonomia das redes pode ser grande, uma vez que têm a possibilidade de conseguir internamente todos os insumos de que necessita, em termos de produção. Por outro lado, considerando-se a característica da competitividade entre redes, caso existam duas ou mais delas com características semelhantes, essa autonomia pode ter impacto menor, em termos de vantagem competitiva.

Para efeito deste trabalho, considera-se a existência de duas redes no Brasil, e de uma rede na Espanha, já descritas no item Caracterização das Redes Estudadas. Esse tipo de comparação pode ser oportuno, uma vez que as redes em análise possuem características comuns: pertencem à mesma indústria, e produzem os mesmos produtos e, em alguns casos, até competem nos mesmos mercados. O cruzamento entre as informações provenientes da descrição das redes e da tipologia apresentada verifica-se no Quadro 3.

Os resultados da aplicação da tipologia relacionam-se tanto ao conjunto das três redes como para cada rede, de modo individual. Com relação ao conjunto de redes analisadas, apesar de apresentarem similaridades estruturais, como sendo da mesma indústria, duas delas em um mesmo país, as três atuando com os mesmos produtos e, em alguns casos, nos mesmo mercados, possuem uma tipologia distinta. A aplicação dessa tipologia permitiu que se pudesse evidenciar com maior precisão onde se encontram essas diferenças. A literatura consultada e o trabalho de campo realizado já apontavam essas diferenças.

Iniciando-se então pela própria referência, sobre a rede de Castellón, pode-se afirmar que, pelo predomínio de pequenas empresas, e por haver maior cooperação tanto entre manufatureiras (competidores) como fornecedores, sua direcionalidade é tanto horizontal como vertical.

O alto grau de concentração (144 empresas de produtos finais em um raio de $25 \mathrm{~km}$ ) corrobora esta inferência. Além disso, tipifica a rede como intensamente 
aglomerada, quando comparada às duas anteriores. Para esta avaliação, tem-se em conta também a existência de grande número de fornecedores locais, como já destacou ASCER (2000).

\section{Quadro 3: Comparação entre Redes}

\begin{tabular}{|c|c|c|c|c|c|c|c|c|c|c|c|c|c|c|c|c|}
\hline \multirow[t]{2}{*}{ Característica } & \multirow{2}{*}{$\begin{array}{l}\text { Tipologia } \\
\\
\text { Escala } \\
\end{array}$} & \multicolumn{5}{|c|}{$\begin{array}{l}\text { Criciúma } \\
\text { (Brasil) }\end{array}$} & \multicolumn{5}{|c|}{$\begin{array}{l}\begin{array}{l}\text { Santa Gertrudes } \\
\text { (Brasil) }\end{array} \\
\end{array}$} & \multicolumn{5}{|c|}{$\begin{array}{l}\text { Castellón } \\
\text { (Espanha) }\end{array}$} \\
\hline & & 1 & 2 & 3 & 4 & 5 & 1 & 2 & 3 & 4 & 5 & 1 & 2 & 3 & 4 & 5 \\
\hline \multirow[t]{2}{*}{ Direcionalidade } & Vertical & & & & $\mathrm{X}$ & & & & & $\mathrm{X}$ & & & & & & $\mathrm{X}$ \\
\hline & Horizontal & & $\mathrm{X}$ & & & & & & $\mathrm{X}$ & & & & & & & $\mathrm{X}$ \\
\hline \multirow[t]{2}{*}{ Localização } & Dispersa & & & & & & & & & & & & & & & \\
\hline & Aglomerada & & & $\mathrm{X}$ & & & & & $\mathrm{X}$ & & & & & & & $\mathrm{X}$ \\
\hline \multirow[t]{2}{*}{ Formalização } & Base contratual formal & & & & $\mathrm{X}$ & & & & & & & & & & & \\
\hline & Base não contratual & & & & & & & & & $\mathrm{X}$ & & & & & & $\mathrm{X}$ \\
\hline \multirow[t]{2}{*}{ Poder } & Orbital & & & & $\mathrm{X}$ & & & & & & & & & & & \\
\hline & Não orbital & & & & & & & & & $\mathrm{X}$ & & & & & & $\mathrm{X}$ \\
\hline
\end{tabular}

Fonte: elaboração própria a partir da pesquisa de Hoffmann (2002).

A base não contratual deriva de dois pontos principais: o tamanho típico das empresas e também a existência de relações que vão além daquelas puramente econômicas (Molina-Morales et al., 2001). As pessoas nascem, crescem e abrem seus negócios no local, permitindo que as relações entre elas sejam redundantes e se criem fortes vínculos, tal como acontece em outros casos similares estudados (Kristensen, 1993).

Tanto pelo tamanho, como pelo tipo de relações e grau de formalização, notase a inexistência de um centro de poder, o que configura esta rede como não orbital. Ressalta-se também que o próprio associativismo intenso, existente localmente, permite que o poder de decisão constantemente troque de mãos.

A análise dos resultados para a rede com sede em Criciúma mostra que há uma bi-direcionalidade. Isto é, as empresas estão presentes em redes verticais, com fornecedores; contudo, por serem mais integradas, necessitam de menor interação com fornecedores. Desde o ponto de vista da horizontalidade, a incidência de cooperação é menor, e cada ator busca sua auto-suficiência individual.

Em termos de localização, o que se verifica é que a indústria estudada é menos aglomerada. A aglomeração reúne cerca de dezoito empresas, em um raio de 55 quilômetros. Também coexistem fornecedores localmente, que acabam por reforçar a estrutura industrial, mas em menor intensidade daquela verificada na Espanha.

As bases contratuais são formais. A maioria das empresas de Criciúma tem a administração profissional e/ou mista, o que pressupõe a formalidade, até 
como mecanismo de controle por parte dos investidores. Fica difícil desenvolver relações na base da confiança, quando o tomador de decisões e o dono de capital são sujeitos distintos. O primeiro está condicionado às necessidades do segundo; mas ainda nesse caso as relações são formais, com base contratual.

Como último indicador para esta rede, salienta-se o fato de que ela se constitui como orbital, com dois centros de poder. A maioria das empresas se relaciona com uma ou outra empresa, e essa escolha pressupõe a eliminação da empresa oposta. Seria o mesmo que pensar que existem duas sub-redes dentro dessa rede aglomerada. Como possuem maior número de funcionários, maior volume de produção, e maior valor faturado, essas duas grandes empresas acabam por influenciar mais nas decisões conjuntas.

Em Santa Gertrudes, a verticalização é menor e a horizontalização mais intensa. A verticalização menor se explica em parte pelo tamanho das empresas. Também se salienta que essas empresas têm no local a oferta de serviços especializados, ainda que de maneira apenas embrionária, quando comparados àqueles presentes em Castellón. A horizontalização se dá em função de distintas necessidades comuns, que acabaram por forçar as inter-relações das partes. Iniciativas como a constituição de um centro tecnológico, e outras relacionadas ao meio ambiente ecológico, contribuíram para isso.

Quanto à localização, existe a concentração, mas não com a mesma estrutura constatada em Castellón. Percebe-se que, em termos de número de plantas industriais, que é um indicador já utilizado para se verificar a concentração de uma indústria (Martínez-Fernandez, 2001; Molina-Morales, 1997), Santa Gertrudes apresenta um quadro de maior intensidade que aquela verificada em Criciúma. As empresas são menores e isso também pode ter relação com o número de plantas instaladas.

As empresas de Santa Gertrudes são empreendimentos com baixo grau de formalização. Em parte, isso pode ser explicado pela presença dos detentores do capital no comando dos negócios, o que pode estar permitindo flexibilidade maior nos negócios. Além disso, os empresários se conhecem em função de que muitos apresentam graus de parentesco entre si, além de virem de uma indústria oleira anterior $^{(4)}$, que se caracteriza por este tipo de comportamento, em termos contratuais. Como já foi salientado, a informalidade foi uma das bases de sustentação do crescimento da própria indústria.

Por fim, em relação ao poder, as empresas, por terem tamanho muito semelhante, não são capazes de influenciar decisivamente suas competidoras, nem seus fornecedores. Além disso, com estratégia voltada à liderança em custos, cada 
empresa procura desenvolver produtos a partir daqueles já existentes, muitas vezes lançados por competidores locais, ou mesmo de outras regiões.

\section{CONCLUSÃo}

Este artigo teve por objetivo propor uma tipologia para a classificação das redes de empresas. Pode-se dizer, no final de nossos estudos, que as redes podem estar constituídas, segundo Gomes-Cásseres (1994), através de vários tipos de alianças, que vão das formais até as informais. Esses distintos tipos de configuração são formatados pelo escopo que a rede pode ter. Isso significa que não há um tipo ideal de rede; mas diferentes tipos de situações de mercado podem levar a diferentes acordos e interações das empresas.

Foram apresentadas várias definições para o termo redes de empresas, e se optou por aquela relacionada ao texto de Jarillo (1988), que considera que são acordos de longo prazo entre empresas distintas, ainda que se tenha considerado, para efeitos deste trabalho, também as instituições de suporte industrial, como associações, centro de tecnologia e universidades. $\mathrm{O}$ escopo das redes, segundo esse mesmo autor, é alcançar e/ou sustentar uma vantagem competitiva em face dos competidores.

A literatura consultada e os casos estudados permitiram o desenvolvimento de uma tipologia vinculada a quatro indicadores: direcionalidade, localização, formalização e poder. Para ilustração da aplicação dessa tipologia, foram consideradas três redes dentro da indústria de cerâmica de revestimento, duas no Brasil e uma na Espanha. A partir dos dados levantados com distintos instrumentos, pôde-se aplicar a tipologia, e inferir a especificidade de cada rede e seu grau de aproximação com a rede considerada mais ajustada às tipologias.

Esse exercício mostrou as diferenças entre essas redes. Algumas dessas diferenças evidenciam que, dentro de uma mesma indústria, e até dentro de um mesmo país, as redes podem ser estruturas singulares e similares ao mesmo tempo. Isso parece mostrar que, para a aplicação da tipologia proposta, é necessário utilizar como âmbito de análise a rede e não o país, visto que, como se encontra na ilustração, pode haver mais redes de uma mesma indústria em um mesmo país.

Nosso estudo também mostrou que, dependendo da referência que se utilize, pode-se analisar a aproximação de cada rede à referência dada. Para tanto é necessário estudar as redes, desde sua constituição. Assim, uma abordagem de pesquisa que inclua aspectos qualitativos pode ser necessária. Caso contrário, a tarefa de explicar cada ponderação na tipologia pode tornar-se complexa. Ainda 
sobre os modelos de referência, sua aplicação parece que tornou a tipologia empregada mais elucidativa. Contudo pode-se empregar a tipologia sem uma referência, no sentido de descrever as redes e entender seu funcionamento, mais que compará-las. Levanta-se, então, a possibilidade de estudos focados mais na classificação que na comparação propriamente dita.

Ressalta-se que na tipologia proposta não foi assinalada a tipologia dispersa na característica localização, uma vez que as três redes estudadas se configuram como aglomeradas. Porém dispersão e aglomeração parecem representar um contínuo, que deve ser levado em conta, quando as redes em análise apresentam ambas as características.

Outra reflexão que se pode fazer é que a tipologia proposta avança para além dos dois eixos tradicionais de caracterização ou tipologia de redes, que são a direcionalidade e a formalização. A incorporação de indicadores para poder e localização permite que, em uma mesma tipologia, distintos tipos de redes possam ser classificados, além de possibilitar uma releitura dos eixos tradicionais.

Pode-se pensar também que outras tipologias têm permitido a classificação de diversos tipos de redes. A proposta apresentada vem contribuir com essa linha. Apesar de a ilustração empírica aplicada ser especificamente de empresas aglomeradas, outros trabalhos podem avançar no sentido de entender melhor as redes dispersas, refletindo se a localização se relaciona com outros indicadores, como poder, por exemplo.

Os limites deste trabalho são relativos à aplicação da escala, o que se tentou amenizar com o uso de uma rede como referência. Outro limite é que, apesar de se ter de conhecer a formação da rede, essa tipologia retrata, sobretudo, o presente de cada uma delas. É possível que, com o passar do tempo, e pelo próprio processo de dinamicidade das redes, essa tipologia, quando aplicada, retrate outra realidade.

A aplicação de tal tipologia parece pertinente, em termos de classificação e pode ser desenvolvida como contribuição para o estudo das redes de empresas. Alguns caminhos para esse desenvolvimento seriam a aplicação dessa tipologia em outras indústrias e mesmo a aplicação desse modelo na rede aglomerada da indústria de cerâmica de revestimento da Itália e da Turquia que, como o Brasil e a Espanha, estão entre os maiores produtores e exportadores mundiais. Outra fronteira para novos estudos, a partir deste trabalho, está na possibilidade do aprimoramento da tipologia proposta, visto que as redes, como fenômenos socioeconômicos, igualmente estão sujeitas à dinamicidade e novas configurações existentes podem demandar mudanças na tipologia proposta.

Artigo recebido em 31.05.2005. Aprovado em 16.12.2005. 


\title{
NOTAS
}

\begin{abstract}
${ }^{1}$ Os autores agradecem aos revisores anônimos da Revista de Administração Contemporânea por suas críticas, sugestões e contribuições. Igualmente, agradecem o apoio material à parte dessa pesquisa pela FAPESC - Fundação da Amparo à Pesquisa de Santa Catarina, com o projeto FCTP1531/034.
\end{abstract}

${ }^{2}$ Se bem que, neste caso, o conceito envolve também um componente de regionalização. Mesmo assim, os DI são citados como exemplo de redes também por Miles e Snow (1986), quando falam de subcontratação.

${ }^{3}$ Pelo tipo de matéria-prima utilizada na região, deve-se destacar que parte das argilas utilizada vem da região do Vale do Rio Tijucas, em Santa Catarina.

${ }^{4}$ Antes de se tornar uma aglomeração de cerâmica de revestimento existia no local grande concentração de fabricantes de cerâmica estrutural.

\section{ReferênCIas Bibliográficas}

Amato Neto, J. (2000).

Redes de cooperação produtiva e clusters regionais. São Paulo: Atlas.

Amato Neto, J. (Org.). (2005).

Redes entre organizações: domínio do conhecimento e da eficácia operacional. São Paulo: Atlas.

Araújo, A.,

Romachelli, J. C., \&

Martins, M. F. (2001).

Análise crítica do setor de revestimentos cerâmicos no Brasil Parte I: histórico recente. Cerâmica Industrial, 6(4), 29-32.

Asociación Española de Fabricantes de Azulejos, Pavimentos y Baldosas Cerámicas (2000).

El sector Español de Fabricantes de Baldosas Cerámicas 1999. Área de Estudios y Asuntos Económicos (Relatório Anual). Castellón, Espanha.
Asociación Española de Fabricantes de Azulejos, Pavimentos y Baldosas Cerámicas (2002).

El sector Español de Fabricantes de Baldosas Cerámicas 2001. Área de Estudios y Asuntos Económicos (Relatório Anual). Castellón, Espanha.

Balestrin, A., \&

Vargas, L. M. (2003).

A dimensão estratégica das redes horizontais de PMES: teorização e evidências. Anais do Encontro de Estudos em Estratégia, Curitiba, PR, Brasil, 1.

Bauer, M. A. L. (2003).

Redes e identidades: perspectivas estratégicas e institucionais. Anais do Encontro Nacional dos Programas de Pós-graduação em Administração, Atibaia, SP, Brasil, 27. 
Caridade, M. D., \&

Torkomian, A. L. V. (2001).

Estratégias de produção das empresas cerâmicas de Santa Gertrudes. Cerâmica Industrial, 6(1), 32-39.

Carrão, A. M. R. (2004).

Cooperação entre empresas de pequeno porte em pólos industriais: um estudo comparativo. Revista de Administração, 39(2), 186-195.

Casarotto Filho, N., \&

Pires, L. H. (2001).

Redes de pequenas e médias empresas e desenvolvimento local: estratégia para a conquista da competitividade global com base na experiência italiana. São Paulo, Atlas.

Castells, M. (1999).

A era da informação: economia sociedade e cultura - a sociedade em rede. São Paulo: Paz e Terra.

Cavalcante, F. B. F., \&

Arruda, D. M. O. (2003).

Estratégias para geração de desempenho financeiro em franchising. Anais do Encontro de Estudos em Estratégia, Curitiba, PR, Brasil, 1.

Coelho, J. M.,

Suslick, S. B., \&

Souza, M. C. A. F. (2000).

Uma abordagem sobre a indústria de Fledspato no Brasil. Cerâmica Industrial, 5(1), 40-42.

Drucker, P. (1994).

Sociedade pós-capitalista. Rio de Janeiro: Campus.
Dyer, J. H. (1996).

Specialized supplier networks as a source of competitive advantage: evidence from the auto industry. Strategic Management Journal, 17(4), 271-291.

Enright, M. J. (1998).

Regional clusters and firm strategy. In A. Chandler, Jr., P. Hagström, \& Ö. Sölvell (Eds.). The dynamic firm: the role of technology, strategy, organization, and regions. London: Oxford University Press.

Esser, K.,

Hillebrand, W.,

Messner, D., \&

Meyer-Stamer, J. (1994).

Competitividad sistémica: competitividad internacional de las empresas y políticas requeridas. Berlín: Instituto Alemán de Desarrollo, Estudios e Informes.

Ferreira, H. C., \&

Wilhelm, P. P. H. (2001).

Cluster $\mathrm{CMB} / \mathrm{SC}$ : perspectivas para o desenvolvimento do segmento cama, mesa e banho da indústria têxtil de Santa Catarina na virada do milênio. Anais do Encontro Nacional dos Programas de Pós-Graduação em Administração, Campinas, SP, Brasil, 25.

Foss, N. J., \&

Koch. C.A. (1996).

Opportunism, organsational economics and the network approach. Scandanavian Journal of management, 12(2), 189-205. 
Gomes-Casseres, B. (1994)

Group versus Group: how alliance networks compete. Harvard Business Review, 72(4), 62-74.

Goularti Filho, A. (2001). A história do setor cerâmico Catarinense. (Relatório não publicado).

Grandori, A., \&

Soda, G. (1995)

Inter-firm Network: antecedents, mechanisms and forms. Organization Studies, 16(2), 183-214.

Granovetter, M. (1985)

Economic action and social structure: the problem of embeddedness. American Journal of Sociology, 91(3), 481-510.

Håkansson, H., \&

Snehota, I. (1989).

No business is an island: the network concept of business strategy. Scandinavian Journal of Management, 5(3), 187-200.

Hall, R. A. (1992).

The strategic analysis of intangible resources. Strategic Management Journal, 13(2), 135-144.

Hall, R. A. (1993).

A Framework linking intangible resources and capabilities to sustainable competitive advantage. Strategic Management Journal, 14(8), 607-618.

Hansen, N. (1992).

Competição, confiança e reciprocidade no desenvolvimento de ambientes regionais inovadores. Papers in Regional Science: The Journal of the RSAI, 71(2), 95-105.
Henry, N.,

Oinch, S., \&

Russel, S. (1996).

In pole position? Untraded interdependencies, new industrial spaces as the british motor sport industry. Area, 28(1), 25-36.

Hoffmann, V. E. (2002).

Los fatcores competitivos de la empresa a partir de la perspectiva de los distritos industriales. Um estudio de la industria cerámica de revestimiento brasileña. Tese de doutorado não publicada, Universidad de Zaragoza, Zaragoza, Espanha.

Hoffmann, V. E. (2004).

Transferência de conhecimento entre empresas aglomeradas territorialmente: um estudo na indústria de confecção do Vale do Itajaí. Projeto de pesquisa FCTP1531/034, Fundação de Apoio à Pesquisa Científica e Tecnológica do Estado de Santa Catarina, Florianópolis, SC, Brasil.

Jarillo, J. C. (1988).

On strategic networks. Strategic Management Journal, 9(1), 31-41.

Jones, C.,

Hesterley, W. S., \&

Borgatti, S. (1997).

A general theory of network governance: exchange conditions and social mechanism. Academy of Management Review, 22(4), 911-945.

Kristensen, H. (1993).

Distritos industriales en Jutlandia Occidental, Dinamarca. In F. Pyke \& W. Sergenberger (Coords.). Los DI y las PYMEs: DI y regeneración económica local (Colección Economía y Sociología del Trabajo). Madrid: MSSS. 
Lorenzoni, G., \&

Baden-Fuller, C. (1995).

Creating a strategic center to manage a web of partners. California Management Review, 37(3), 146-163.

Martínez-Fernández, M. T. (2001).

El modelo explicativo de la competitividad de la empresa en los distritos industriales: el efecto de los recursos compartidos. Tesis Doctoral no publicada, Universitat Jaume I, Castellón, España .

Meyer-Stamer, J. (1998).

Path dependence in regional development: persistence and change in three industrial clusters in Santa Catarina, Brazil. World Development, 26(8), 1495-1511.

Meyer-Stamer, J. (1999, October).

What can business associations do to stimulate regional economic development? Experience from Santa Catarina, Brazil. International Institute for Labor Studies/ ILO Caribbean Office Regional Workshop and Global Competition: New Roles for Enterprises and their Organizations (Relatório de Trabalho), Port of Spain, Trinidad e Tobago.

Meyer-Stamer, J.,

Maggi, C., \&

Siebel, S. (2001).

Improving upon nature. patterns of upgrading in ceramic tile clusters in Italy, Spain, and Brazil. Draft Report for the Joint IDS/INEF Research Project: The Interaction of Global and Local Governance Implications for Industrial Upgrading (Relatório de Trabalho), IDS, Bonn, Alemanha.
Miles, R. E., \&

Snow, C. C. (1986).

Organizations: new concepts for new forms. California Management Review, 28(3), 62-73.

Molina-Morales, F. X. (1997).

Sistemas productivos descentralizados: factor territorio y estrategias empresariales. Tesis doctoral no publicada, Universitat Jaume I, Castellón, Espanha.

Molina-Morales, F. X. (2001a).

Human capital in the industrial districts. Human Systems Management, 20(4), 319-331.

Molina-Morales, F. X. (2001b).

Proyecto de investigación: influencia del contexto institucional en los factores determinantes de la competitividad empresarial: un análisis del efecto territorio (Projeto de pesquisa - GV00-021-8), Universidad Jaume I, Castellón de la Plana, Referencia GV00-021-8.

Molina-Morales, F. X.,

López-Navarro, M. A., \&

Guia-Julve, J. (2001).

Social capital in territorial agglomerations of firms: opportunities and restraints. Conference of the European Group for organizational Studies (EGOS), 17, Lyon, França

Oliveira, Jr, M. M.,

Sommer, P. S.,

Colombini, F. B., \&

Ikebe, N. T. (2001).

Transferência de conhecimento e best practices em redes corporativas globais. Anais do Encontro dos Programas Nacional de PósGraduação em Administração, Campinas, SP, Brasil, 25. 
Oliveira, L. A. G., \&

Batista, P. C. S. (2001).

As pequenas empresas e as alianças estratégicas: tendências e oportunidades a partir da análise do pólo calçadista de Fortaleza. Anais do Encontro Nacional dos Programas de Pós-Graduação em Administração, Campinas, SP, Brasil, 25.

Paiva, Jr., F. G., \&

Barbosa, F. V. (2001).

Redes organizacionais no sistema de cluster: reflexões sobre sua posição estratégica na busca de oportunidades pelas pequenas e médias empresas. Encontro Nacional dos Programas de Pós-Graduação em Administração, Campinas, SP, Brasil, 25.

Pereira, B A. D., \&

Pedrozo, E. E. (2003).

Modelo de análise do comportamento de redes inter-organizacionais sob o prisma organizacional. Encontro Nacional dos Programas de Pósgraduação em Administração, Atibaia, SP, Brasil, 27.

Pinch, S., \&

Henry, N. (1999).

Paul Krugman's geographical economics, industrial clustering and the British motor sport industry. Regional Studies, 33(9), 815-827.

Pitassi, C., \&

Macedo-Soares, T. D. L. V. A. de (2003). Redes estratégicas virtuais: fatores críticos de sucesso. Revista de Administração Contemporânea, 7(Edição especial), 75-99.

Porter, M. (1980).

Competitive strategy: techniques for analyzing industries $e$ and competitors. New York: The Free Press.

Powell, W. W. (1990).

Neither market nor hierarchy: networks forms of organization. Research in Organizational Behavior, 12, 295-336.

Prahalad, C. K., \&

Hamel, G. (1994).

Strategy as a field of study: why search for a new paradigm. Strategic Management Journal, 15(5), 5-16.

Ramírez, R. (1999).

Value co-production: intellectual origins and implications for practice and research. Strategic Management Journal, 20(1), 49-65.

Richardson, R. J. (1999).

Pesquisa social: métodos e técnicas. São Paulo: Atlas.

Schmitz, H. (1993).

Distritos industriales: modelo y realidad en Baden-Württenberg Alemania. In F. Pyke \& W. Sergenberger (Coords.). Los DI y las PYMEs: DI y regeneración económica local (Colección Economía y Sociología del Trabajo). Madrid: MSSS.

Sindicato das Indústrias da Construção e do Mobiliário de Santa Gertrudes (1998).

Características Gerais (Relatório de Trabalho), Santa Gertrudes, SP.

Siqueira, M. M. (2000).

Redes sociais na gestão de serviços urbanos. Revista de Administração Pública, 34(6), 179-198. 
Storper, M., \&

Harrison, B. (1991).

Flexibility, hierarchy and regional development: the changing structure of industrial production systems and their forms of governance in the 1990s. Research Policy, 20(5), 407-422.

Teixeira, F., \&

Guerra, O. (2002).

Redes de aprendizado em sistemas complexos de produção. Revista de Administração de Empresas, 42(4), 93-105.

Thorelli, H. B. (1986).

Networks: between markets and hierarchies. Strategic Management Journal, 7(1) 37-51.

Uzzi, B. (1996).

The sources and consequences of embeddedness for the economic performance of organizations: the network effect. American Sociological Review, 61(4), 674-698.
Vet, J. M. de, \&

Scott, A. J. (1992).

The southern Californian medical device industry: innovation, new firm formation, and location. Research Policy, 21(2), 145-161.

Williamson, O. E. (1975).

Markets and Hierarchies. New York: Free Press.

Williamson, O. E. (1991).

Comparative economic organization: the analysis of discrete alternatives. Administrative Science Quarterly, 36, 269-296.

Wittmann, M. L.,

Negrini, F., \&

Venturini, T. (2003).

As redes empresariais como uma alternativa para aumentar a competitividade de empresas do setor de comércio varejista. Anais do Encontro de Estudos em Estratégia, Curitiba, PR, Brasil, 1. 